\title{
Risk factors for acute kidney injury after liver transplantation
}

\author{
Dana Tomescu ${ }^{1,2}$, Mihai Popescu², Simona Olimpia Dima ${ }^{3}$, Vladislav Brașoveanu ${ }^{3}$, Irinel Popescu ${ }^{2,3}$
}

${ }^{1}$ Fundeni Clinical Institute, Department of Anaesthesia and Critical Care III

2"Carol Davila" University of Medicine and Pharmacy, Department of Anaesthesia and Critical Care

3"Dan Setlacec" Center of General Surgery and Liver Transplantation

Fundeni Clinical Institute, Bucharest, Romania

\author{
Corresponding author: \\ Dana Tomescu MD, PhD \\ Associate Professor "Carol Davila" \\ University of Medicine and Pharmacy \\ Department of Anaesthesia and \\ Critical Care III, Fundeni Clinical \\ Institute, 258 Fundeni Street, \\ Bucharest, Romania \\ E-mail: danatomescu@gmail.com
}

\section{ABSTRACT}

Introduction: Liver transplantation (LT) represents the only definitive treatment in End-Stage Liver Disease (ESLD). Patient outcome, including quality of life after LT depends on perioperative outcome and reduction of postoperative complications. Many studies identified acute kidney injury (AKI) as one of the most frequent complications after liver transplantation with a negative impact on both short and long term survival, and focused on identifying risk factors for AKI. Our aim is to assess modifiable risk factors in a single national center in a country that is stii under development in order to improve our clinical practice.

Methods: We collected retrospective data from 112 patients who underwent liver transplantation at Fundeni Clinical Institute, Bucharest between January 2012 and May 2013. Patients with acute liver failure and pre-existing renal dysfunction were excluded. Analyzed data were: demographic variables, severity of ESLD (assessed by severity scores and paraclinical variables) and co-morbidities, intraoperative blood loss and transfusion, intraoperative haemodynamics and vasopressor requirements, postoperative incidence of AKI and chronic kidney disease (CKD) and outcome (Post Anaesthesia Care Unit Length of Stay and mortality).

Results: The overall incidence of postoperative AKI was 35.77\% $(n=39)$ in the 109 patients included in the final analysis: AKI I $(64.10 \% n=25)$, AKI II $(23.07 \% n=9)$ and AKI III $(12.83 \%$ $n=5)$. Variables that correlated with AKI included: recipient age $(p=0.006)$, cardiovascular disease $(p=0.015)$, MELD-Na score $(p=0.035)$, bilirubin $(p=0.016)$, albumin $(p=0.048)$. Univariate analysis identified intraoperative blood loss $(p=0.010)$, Packed Red Blood Cells (RBC) $(p=0.006)$ and Fresh Frozen Plasma (FFP) $(p=0.001)$ transfusion and high-dose vasopressor support $(p=0.034)$ as predictors of AKI. One year survival was significantly reduced in the 39 patients with $\mathrm{AKI}(79,5 \%)$ compared to patients without AKI in the early postoperative period $(92,3 \%)$.

Conclusion: In conclusion, patients age, serum bilirubin and albumin levels, MELD-Na score, co-existing cardiovascular disease and intraoperative high vasopressor support represent risk factors for AKI after LT. Therefore, it is essential to early identify and correct - if possible- these factors in order to increase the efficiency of therapeutic management of renal disease.

Key words: liver transplantation, acute kidney injury, chronic kidney disease, postoperative outcome

\section{INTRODUCTION}

Clinical modeling identified serum creatinine as one of three objective out-

Copyright ( $)$ Celsius Publishing House 
come measures in the Model for End Stage Liver Disease (MELD); a clinical tool that predicts the risk of death on the liver transplantation (LT) wait list (1). This prioritized organ allocation to patients with renal dysfunction (2-5) and may have led to an increase in the number of patients with post transplant renal insufficiency or failure. Between $17 \%$ - $95 \%$ of all transplant recipients will experience AKI in the immediate postoperative period (6-8). In addition, AKI is a risk factor for the development of chronic kidney disease (CKD) following LT $(9,10)$.

Postoperative complications of liver transplantation can be difficult and expensive to treat. Renal failure requires significant personnel and equipment. Availability of renal replacement therapy or subsequent kidney transplantation is not as readily available in all developing nations. Recent evidence shows that morbidity and mortality due to AKI and renal failure are greater in countries with fewer resources (11). Therefore the risk of post liver transplantation renal failure may influence medical care or organ allocation in developing nations.

There are a number of well recognized risk factors for the development of AKI following liver transplantation. Preoperative conditions such as hepatorenal syndrome, spontaneous bacterial peritonitis, severity of disease, co-morbidities (such as diabetes, and hepatitis $\mathrm{C}$ infection) increase the risk of renal insufficiency and failure (12-15). Intraoperative management and donor graft integrity also influence renal outcome.

These data were derived from the study of patient populations with well-developed medical infrastructure and established liver transplantation programs. However, developing countries with fewer medical resources are establishing liver transplantation programs in order to care for their own populations. Differences in the availability of medical care, or specialty care could affect the pre and postoperative outcome of patients with renal injury.

Romania established a single center liver transplantation program in the year 2000. The center currently allocates organs using MELD criteria. There has been rapid growth from the first year where 9 transplants were performed to 122 procedures in 2013. After the country emerged from a recent economic crisis, there were not enough resources to care for all patients who needed a lifesaving transplant. Healthcare providers therefore questioned what impact AKI had on liver transplant outcome in developing nations such as Romania and if changes in the medical system were needed to reduce post transplantation renal injury.

Our aim was to assess how well variables associated with an increased risk of AKI in developed countries predicted kidney outcome in our single national center. Therefore, we examined the incidence of postoperative AKI in our patients and the conversion to chronic renal failure at one year postoperatively.

\section{MATERIAL AND METHOD}

\section{Data Collection \\ Patient population and clinical definitions:}

The Ethical Committee of Fundeni Clinical Institute, Bucharest, Romania, granted institutional approval for the present study in accordance with principles of the Declaration of Helsinki. The data from 112 patients who underwent liver transplantation at Fundeni Clinical Institute, Bucharest between January 2012 and May 2013 were collected retrospective. Patients with pre-existing renal dysfunction (serum creatinine $>1.4$ $\mathrm{mg} / \mathrm{dl}$ or requiring renal replacement therapy), under age 14, who underwent re-transplantation and patients who died within 24 hours after surgery were excluded from study. Data were collected at three phases of care: the preoperative, intraoperative and early postoperative period.

Renal disease was defined using the International Ascites Club diagnosis criteria for hepatorenal syndrome (16). AKI was defined according to Acute Kidney Injury Network (AKIN) as recommended by the 2007 Amsterdam Guidelines (17). CKD was defined by a decrease in estimated Glomerular filtration rate (GFR) below $60 \mathrm{ml} / \mathrm{min}$ or serum creatinine $(\mathrm{SCr}$ ) levels above $1.4 \mathrm{mg} / \mathrm{dL}$ for at least three consecutive months (18). We used a serum creatinine of $1.4 \mathrm{mg} / \mathrm{dL}$ and based a diagnosis of AKI on the peak serum creatinine obtained within 7 days after surgery. The time period agrees with current recommendations (17). Criteria to start renal replacement therapy for AKI were based upon published recommendation (19).

\section{Intraoperative management}

Patients underwent general anesthesia using a rapid sequence induction; Propofol $(1-2 \mathrm{mg} / \mathrm{kg})$, Fentanyl $(20-40 \mu \mathrm{g} / \mathrm{kg}$ ) and Succinylcholine $(1 \mathrm{mg} / \mathrm{Kg})$. General anesthesia was maintained using Sevoflurane (1-2\%), continuous infusion of Fentanyl $(0.03 \mu \mathrm{g} / \mathrm{kg} / \mathrm{min})$ and bolus dosing of Atracurium (monitored by response to a train of four stimulation using the radial nerve). A 16 G, 3 port central venous catheter was placed in either the internal jugular vein or subclavian vein. A $20 \mathrm{G}$ radial arterial catheter was placed for continuous monitoring of blood pressure. 
Cardiac output monitoring was performed through a pulmonary artery catheter or pulse contour analysis with a PICCO Plus ${ }^{\circledast}$ (Pulsion Medical Systems, Munich, Germany). Rotational thromboelastometry was used to guide coagulation management and target hemoglobin of $8.0 \mathrm{~g} / \mathrm{dL}$ guided the administration of packed red blood cells. Total vascular exclusion for hepatectomy was used in orthotopic LT recipients.

Intraoperative immunosuppression consisted of 500 mg methylprednisilone during the anhepatic phase (except for Hepatitis Virus C etiology) and $20 \mathrm{mg}$ of basiliximab during the neohepatic phase. A second dose of basiliximab was given on postoperative day 4, and day 5 with either cyclosporine or tacrolimus combined with mycophenolat mofetil (withdrawn in patients with leukocytes levels below $2000 / \mu$ l or platelets count under $25000 / \mu l)$.

\section{Study variables}

Preoperative variables were: type of liver transplantation (live vs. cadaveric donor), age, sex, MELD and MELD-Na scores, Child-Pugh score, co-morbidities (known ischemic heart disease and diabetes mellitus). Laboratory variables included serum sodium, bilirubin, albumin, creatinine and glomerular filtration rate (estimated using Cockroft-Gault formula)

Intraoperative variables included hypotension (a mean pressure $<55 \mathrm{mmHg}$ for $\geq 30$ consecutive minutes), estimated blood loss, units of red blood cells (RBC) and fresh frozen plasma (FFP) transfused, duration of anhepatic phase and presence of reperfusion syndrome; defined in accordance with Hilmi et al. (20) as severe post-reperfusion hypotension (more then $30 \%$ of the anhepatic level), asystole or hemodynamic significant arrhythmias. The postoperative variables included length of stay (LOS) and renal outcome (serum creatinine and urinary output).

Serum creatinine was used to assess renal function in the early postoperative period. Laboratory variables were collected at $8 \mathrm{~h}$ intervals during the first 3 days after surgery, and then twice daily until discharge from Post - Anaesthesia Care Unit (PACU). Subsequent monitoring of renal function was performed at 1 month, 3 months and 6 months intervals after LT.

\section{Statistical analysis}

Our analysis was designed to identify variables from the preoperative and intraoperative period that were associated with the onset of AKI in our patients. Therefore we performed a univariate analysis of variables identified as predictive in previous studies. Significance for a two tailed test and correlation coefficients were calculated. Correlation coefficients were calculated using the Pearson's equation to estimate the degree of dependence between individual variables and AKI. A multivariate analysis was then used to identify the subset of variables with the greatest correlation with AKI.

Data are presented as mean \pm standard deviation of the mean, median ( $\min , \mathrm{max}$ ) otherwise percentage. Data distribution was examined in order to insure the proper statistical examination. The univariate analysis of recorded data was performed to identify factors predictive for AKI. Categorical variables were analyzed with Chi-square test and quantitative data were analyzed with independent samples t-test. Mann-Whitney test was used when the analyzed data did not follow a normal distribution. For multivariate analysis of data considered significant in univariate analysis a binary logistic regression was used. All P values are two-tailed. Statistical significance was considered at a $p$-value $<0.05$. Statistical analysis was performed using SPSS v19.0 (IBM, Armonk, NY)

\section{RESULTS}

\section{Characteristics of study population}

After applying the exclusion criteria 109 patients were included in the final data analysis. Of these, the majority $(79.80 \%, n=87)$ underwent orthotopic LT (OLT) with cadaveric grafts and the remaining living-donor LT. The median age for all transplant recipients was 51.0 years (14-69 years), while the mean MELD/MELD-Na scores were 15.00 (10-30) and 18.0 (10-31) respectively. Mean pre-transplant $\mathrm{SCr}$ level was $0.82 \mathrm{mg} / \mathrm{dL}$. Preoperative data are presented in table 1.

Duration of surgery was 420 minutes (range, 250855 minutes). The median intraoperative blood loss was 5.35 liters ( 0.5 - 30 liters), with a median transfusion of 18.27 units (0-85 units) of fresh frozen plasma (FFP) and 6.94 units (0-35 units) of packed red blood cells (RBC). Twenty-two patients $(20.18 \%)$ were categorized as hemodynamically unstable during surgery and required vasopressor support with high-doses of norepinephrine (median dose $25 \mathrm{mg} / \mathrm{h}$ ( 0 to $28.0 \mathrm{mg} / \mathrm{h}$ ). The mean duration of the anhepatic phase was 44.99 minutes (19108 minutes).

The overall incidence of postoperative AKI was $35.77 \%(n=39)$ in the 109 patients studied. Most of the affected 39 patients had AKI I $(64.10 \% \mathrm{n}=25)$, while fewer had AKI II $(23.07 \% n=9)$ and AKI III $(12.83 \% n=5)$. The median duration of AKI for all 39 patients was 2 days (1-35 days). The median peak $\mathrm{SCr}$ level in this group was $1.89 \mathrm{mg} / \mathrm{dL}$ (1.42 - $5.84 \mathrm{mg} / \mathrm{dL}$ ). Six patients 
Table1 - Univariate analysis of preoperative data in the AKI group vs non-AKI group. * $-p<0.05$

\begin{tabular}{|c|c|c|c|c|}
\hline & All patients $(n=109)$ & AKI $(n=39)$ & Non-AKI $(\mathrm{N}=70)$ & $P$ value \\
\hline Type of LT & & & & 0,999 \\
\hline OLT & $81.65 \%(n=89)$ & $28.44 \%(n=31)$ & $53.21 \%(n=58)$ & \\
\hline LDLT & $18.35 \%(n=20)$ & $7.33 \%(n=8)$ & $11.00 \%(n=12)$ & \\
\hline Age & $51.00 \pm 13.15$ & $52.50 \pm 11.76$ & $46.63 \pm 13.29$ & $0,006^{*}$ \\
\hline MELD score & $15.00 \pm 4.96$ & $16.54 \pm 4.86$ & $15.00 \pm 5.03$ & 0,139 \\
\hline MELD-Na score & $18.00 \pm 6.12$ & $20.21 \pm 6.29$ & $17.38 \pm 5.84$ & $0,035^{\star}$ \\
\hline Serum sodium & & & & 0,078 \\
\hline$\leq 131 \mathrm{mmol} / \mathrm{l}$ & $22.01 \%(n=24)$ & $28.20 \%(n=11)$ & $21.42 \%(n=15)$ & \\
\hline $132-138 \mathrm{mmol} / \mathrm{l}$ & $51.37 \%(n=56)$ & $48.71 \%(n=19)$ & $50.00 \%(n=35)$ & \\
\hline$\geq 139 \mathrm{mmol} / \mathrm{l}$ & $26.60 \%(n=29)$ & $23.09 \%(n=9)$ & $28.57 \%(n=20)$ & \\
\hline Total bilirubin (mg/dl) & $4.15(0.3-31)$ & $5.28(0.3-31)$ & $3.56(0.3-23)$ & $0,016^{\star}$ \\
\hline Albumin (mg/dl) & $3.21 \pm 0.64$ & $3.02 \pm 0.50$ & $3.34 \pm 0.68$ & $0,048^{\star}$ \\
\hline Pretransplant SCr (mg/dl) & $0.89 \pm 0.33$ & $0.94 \pm 0.25$ & $0.86 \pm 0.36$ & $0,046^{\star}$ \\
\hline $\mathrm{GFR}(\mathrm{ml} / \mathrm{min})$ & $102.5 \pm 31.6$ & $97.99 \pm 32.37$ & $104.94 \pm 31.26$ & 0,465 \\
\hline Cardiovascular pathology & $9.17 \%(n=10)$ & $17.94 \%(n=7)$ & $4.28 \%(n=3)$ & $0,015^{\star}$ \\
\hline Diabetes mellitus & $12.84 \%(n=14)$ & $12.82 \%(n=5)$ & $12.85(n=9)$ & 0,613 \\
\hline
\end{tabular}

with AKI (15.38\%) required RRT using veno-venous ultrafiltration in the first month after surgery.

\section{Risk factors for AKI}

Preoperative Predictors: In the preoperative period, a number of variables were associated with a diagnosis of AKI following transplantation in the univariate analysis. Variables that correlated with AKI included: recipient age $(p=0.006)$, cardiovascular disease $(p=$ $0.015)$, MELD-Na score $(p=0.035)$, bilirubin $(p=0.016)$, albumin $(\mathrm{p}=0.048)$ Data are presented in table 1. Significant correlation coefficients for peak postoperative $\mathrm{SCr}$ determined by Pearson correlation were: patient age ( $p=0.001$, correlation coefficient: 0.229 ), MELD-Na ( $p=0.009$, correlation coefficient: 0.293 ), bilirubin levels ( $p=0.004$, correlation coefficient: 0.291 ) and serum sodium levels ( $p=0.019$, correlation coefficient: -0.227). However, only recipient's age $(p=0.018)$ and bilirubin level $(p=0.048)$ remained significant predictors for AKI in the multivariate analysis.

Intraoperative Predictors: Univariate analysis identified intraoperative blood loss $(p=0.010), R B C$ $(p=0.006)$ and FFP ( $p=0.001)$ transfusion and high-dose vasopressor support ( $p=0.034$ ) as predictors of AKI. The number of units of RBC and FFP dropped out during the multivariate analysis and only high-dose of vasopressor support ( $p=0.026$ ) and blood loss during surgery $(p=0.021)$ remained statistically significant for AKI.

\section{CKD after liver transplantation}

The incidence of CKD for the 109 study subjects after the six month follow up was $10.09 \%(n=11)$ A total of 5 of 39 patients had a diagnosed with AKI 39
(12.82\%) while 6 of the remaining patients without postoperative AKI (8.57\%) developed CKD. Peak SCr levels in the early postoperative period $(p=0.005)$ and at one month follow-up $(p=0.001)$ were significantly correlated with the presence of CKD ar 6 months after LT.

\section{Outcomes following transplantation}

The 1 year survival rate of 109 patients was $88.4 \%$ (figure 1). One year survival was significantly reduced in the 39 patients with AKI $(79,5 \%)$ compared to patients without AKI in the early postoperative period (92,3\%). The average Post Anaesthesia Care Unit stay was 8 days for patients without AKI (5-34 days) compared to 12

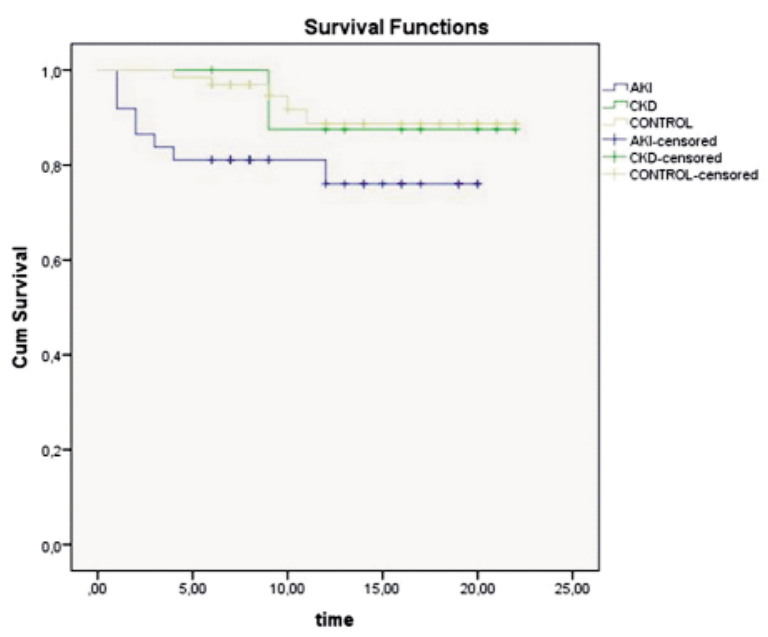

Figure 1 - Comparison of 1 year survival between patients with and without AKI 
days (7-77 days) in patients with AKI $(p<0.008)$.

Two patients out of 11 who developed CKD died during the first year after liver transplantation. None of the patients with CKD got kidney transplants. No significant differences were observed regarding the incidence of AKI and of CKD between cadaveric and living grafts recipients.

\section{DISCUSSIONS}

Our data suggest that age, the severity of liver disease prior to liver transplantation (assessed by MELD-Na score), severe cholestasis and hypoalbuminemia represent the most important pre-transplant factors associated with early onset of AKI after LT. Massive intraoperative blood loss, transfusion of RBC and high-dose vasopressor support represent the most important intraoperative risk factors for AKI. Early postoperative renal dysfunction is associated with an increased incidence of CKD at 6 months after LT and with higher 1-year mortality. The fact that donor risk index was not collected prior to LT and could not be correlated with renal outcome represents the main limitation of our study. Another limitation is represented by the fact that calcineurin inhibitors (tacrolimus) levels were not included in the final analysis and so no estimation could be made on the effect of immunosupression on renal function. Nevertheless, all patients with AKI developed renal impairment prior to tacrolimus administration (before the fifth day).

AKI is an independent prognostic factor for patients with ESLD who undergo LT and is associated with increased morbidity and mortality as demonstrated by many studies (21-22). The prevalence of AKI or CKD among patients on the waiting list for LT is estimated at about $20 \%-30 \%$ at the time of surgery (23-26) but an even higher incidence of AKI is found during the early postoperative period $(27,28)$. To decrease the incidence of AKI in patients with chronic liver disease, current studies evaluate the possibility of performing combined liver-kidney transplant and currently indication criteria are being established for this possibility $(29,30)$.

In the present study, more than one third of patients developed AKI in the postoperative period and $10.09 \%$ of them progressed to CKD 6 months after LT. The different results regarding AKI incidence after $L T$ are generally attributed to different diagnosis criteria for AKI. Thus, defining AKI remains a controversial topic. Two recent studies $(31,32)$ have focused on the definition and classification of renal impairment in patients with cirrhosis and ascites and concluded that a much better risk stratification can be obtained by combining the AKIN criteria and classical criteria of renal failure. Therefore our results were compared with those from other studies in which AKI was defined using the same criteria. The overall incidence of AKI (35.77\%) in the present study is comparable to that reported by: Wei et al. (33)- 28,1\%, Dehghani et al. (34) - 22,9\%, FonsecaNeto et al. (35) - 39\%, but lower than 50-65\% reported in other studies $(12,36)$.

Risk factors for development of AKI in the perioperative period should be well defined in order to find effective strategies to reduce the incidence of AKI. Clinical studies focusing on this issue have reached conflicting results. Our research could not find a significant correlation between MELD score and AKI, but MELD-Na (37) score seems to be a good predictor of postoperative renal impairment as described by Karapanagiotou et al. (38). The lack for a statistical significant correlation between MELD score and renal dysfunction is probably due to the low value of MELD score of our patients. It is interesting to discuss the value of MELD-Na score as a predictor for AKI, because the severity of liver disease might be sometimes better reflected by a high MELDNa score, that reflects a hidden severe portal hypertension with a major risk of bleeding and that sometimes is a predictor for renal impairment even in the absence of a high creatinine level. Further studies are needed to assess the predictive value of MELD-Na score in the settings of liver transplantation.

Diabetes mellitus, identified by different studies $(39,40)$ as an independent risk factor for both acute and chronic renal disease, did not reach statistical significance in the present study.

The duration of the anhepatic phase $(41,42)$, although considered to be a significant risk factor by some authors did not reach statistical significance in the present study. Intraoperative blood loss and RBC transfusion were demonstrated to be significant factors for AKI development in our research - this observation is in agreement with previously published data (43).

Renal replacement therapy (continuous venovenous hemodyalisis) in the first month after surgery was required in $5.50 \%$ of all patients, similar to that published by other authors (44). Published data showed accumulative risk of CKD requiring chronic RRT or kidney transplantation of $5 \%-8 \%$ for the first 10 year $s$ after liver transplantation (45-47).

CKD affects the patient not only in terms of cost and quality-of-life but it is often associated with a significant increase in mortality. The peak $\mathrm{SCr}$ level in the perioperative period is associated with higher levels of $\mathrm{SCr}$ at all times of the follow-up (1, 3 and 6 months). This 
correlation could not be demonstrated by Tinti et al (13). Risk factors for AKI also represent risk factors for chronic renal disease (48). Sharma et al. (49) concluded, after comparing the incidence of renal disease before and after the introduction of MELD score, that a significant increase in the incidence of AKI is probably due to the increasing number of patients with preexisting renal disease at the time of LT.

\section{CONCLUSION}

In conclusion, patients age, serum bilirubin and albumin levels, MELD-Na score, co-existing cardiovascular disease and intraoperative high vasopressor support represent risk factors for AKI after LT. Therefore, it is essential to early identify and correct if possible- these factors in order to increase the efficiency of therapeutic management of renal disease.

\section{The Authors Gratefully Acknowledge}

Special thanks to Prof Dr Susan Mercedes Mandell from the Department of Anesthesiology, University of Colorado and Distinguished Visiting Professor of the National Yang-Ming University, School of Medicine, Taipei, Taiwan for her comments on an earlier version of the manuscript that greatly improved it, although any errors are our own and should not tarnish the reputations of this esteemed person.

\section{Conflict of interest}

The authors have no conflict of interest to declare.

\section{REFERENCES}

1. Boone MD, Celi LA, Ho BG, Pencina M, Curry MP, Lior Y, Talmor D, et al. Model for End-Stage Liver Disease score predicts mortality in critically ill cirrhotic patients. J Crit Care 2014; 29(5): 881.e7-13.

2. Tinti F, Umbro I, Menule A, Rossi M, Merli M, Nofroni I, et al. RIFLE criteria and hepatic function in the assessment of acute renal failure in liver transplantation. Transplant Proc. 2010;42(4):1233-6.

3. Umbro I, Tinti F, Mordenti M, Rossi M, lanni S, Pugliese F, et al. Model for end-stage liver disease score versus simplified acute physiology score criteria in acute renal failure after liver transplantation. Transplant Proc. 2011;43(4):1139-41.

4. Gonwa TA, McBride MA, Anderson K, Mai ML, Wadei H, Ahsan N. Continued influence of Preoperative renal function on outcome of Orthotopic liver transplant (OLTX) in the US: where will MELD lead us? Am J Transplant. 2006;6(11):2651-9.

5. Onaca NN, Levy MF, Sanchez EQ, Chinnakotla S, Fasola CG, Thomas MJ, et al. A correlation between the pretransplantation MELD score and mortality in the first two years after liver transplantation. Liver Transpl. 2003; 9(2):117-23.

6. Moreno JM, Cuervas-Mons V, Rubio E, Pons F, Herreros de T A, Turrion VS, et al. Chronic renal dysfunction after liver transplantation in adult patients: prevalence, risk factors, and impact on mortality. Transplant Proc. 2003;35(5):1907-8.

7. Fraley DS, Burr R, Bernardini J, Angus D, Kramer DJ, Johnson JP. . Impact of acute renal failure on mortality in end-stage liver disease with or without transplantation. Kidney Int. 1998;54(2):518-24.
8. McCauley J, Van Thiel DH, Starzl TE, Puschett JB. Acute and chronic renal failure in liver transplantation. Nephron. 1990;55(2):121-8.

9. Umbro I, Tinti F, Piselli P, Fiacco F, Giannelli V, Di Natale V, et al. Occurence of chronic renal failure in liver transplantation: monitoring of pre- and posttransplant renal function. Transplant Proc. 2012;44(7):1956-9.

10. Tinti F, Umbro I, Giannelli V, Merli M, Ginanni Corradini S, Rossi M, et al. Acute renal failure in liver transplant recipients: role of pretransplantation renal function and 1-year follow-up. Transplant Proc. 2011;43(4):1136-8.

11. Maoujoud O, Zajjari Y, Asseraji M, Aatif T, Ahid S, Oualim Z. Commentary: the practice of dialysis in the intensive care unit in a developing country. Ethn Dis. 2014; 24(2): 226-8.

12. Lima EQ, Zanetta DM, Castro I, Massarollo PC, Mies S, Machado MM, et al. Risk factors for development of acute renal failure after liver transplantation. Ren Fail. 2003;25(4):553-60.

13. Bilbao I, Charco R, Balsells J, Lazaro JL, Hidalgo E, Llopart L, et al. Risk factors for acute renal failure requiring dialysis after liver transplantation. Clin Transplant. 1998;12(2):123-9.

14. Yamamoto S, Sato Y, Ichida T, Kurosaki I, Nakatsuka H, Hatakeyama K. Acute renal failure during the early postoperative period in adult livingrelated donor liver transplantation. Hepatogastroenterology. 2004;51(60): 1815-9.

15. Lee JP, Heo NJ, Joo KW, Yi NJ, Suh KS, Moon KC, et al. Risk factors for consequent kidney impairment and differential impact of liver transplantation on renal function. Nephrol Dial Transplant. 2010;25(8):2772-85.

16. Salerno F, Gerbes A, Gin $\theta$ S P, Wong F, Arroyo V. Diagnosis, prevention and treatment of hepatorenal syndrome in cirrhosis. Gut. 2007 Sep;56(9):13108

17. Mehta RL, Kellum JA, Shah SV, Molitoris BA, Ronco C, Warnock DG, et al. Acute Kidney Injury Network: report of an initiative to improve outcomes in acute kidney injury. Crit Care. 2007;11(2):R31.

18. Levey AS, de Jong PE, Coresh J, El Nahas M, Astor BC, Matsushita K, et al. The definition, classification, and prognosis of chronic kidney disease: a KDIGO controversies conference report. Kidney Int. 2011;80(1):17-28.

19. Gibney N, Hoste E, Burdmann EA, Bunchman T, Kher V, Viswanathan R, Mehta RL, Ronco C. Timing of initiation and discontinuation of renal replacement therapy in AKI: unanswered key questions. Clin J Am Soc Nephrol. 2008; 3(3): 876-80.

20. Hilmi I, Horton CN, Planinsic RM, Sakai T, Nicolau-Raducu R, Damian D, Gligor S, et al. The impact of postreperfusion syndrome on short - term patient and liver allograft outcome in patients undergoing orthotopic liver transplantation. Liver Transpl. 2008; 14(4): 504-8.

21. Zhu M, Li Y, Xia Q, Wang S, Qiu Y, Che M, et al. Strong impact of acute kidney injury on survival after liver transplantation. Transplant Proc. 2010;42(9):3634-8.

22. Narayanan Menon KV, Nyberg SL, Harmsen WS, DeSouza NF, Rosen CB, Krom RA, et al. MELD and other factors associated with survival after liver transplantation. Am J Transplant. 2004;4(5):819-25.

23. Gonwa TA, McBride MA, Anderson $\mathrm{K}$, Mai ML, Wadei $\mathrm{H}$, Ahsan $\mathrm{N}$. Continued influence of preoperative renal function on outcome of orthotopic liver transplant (OLTX) in the US: where will MELD lead us? Am J Transplant. 2006;6(11):2651-9.

24. Hampel H, Bynum GD, Zamora E, El-Serag HB. Risk factors for the development of renal dysfunction in hospitalized patients with cirrhosis. Am J Gastroenterol. 2001;96(7):2206-10.

25. Wu CC, Yeung LK, Tsai WS, Tseng CF, Chu P, Huang TY, et al. Incidence and factors predictive of acute renal failure in patients with advanced liver cirrhosis. Clin Nephrol. 2006;65(1):28-33.

26. Nair S, Verma S, Thuluvath PJ. Pretransplant renal function predicts survival in patients undergoing orthotopic liver transplantation. Hepatology. 2002; 35(5):1179-85.

27. O'Riordan A, Wong V, McQuillan R, McCormick PA, Hegarty JE, Watson AJ. Acute renal disease, as de ned by the RIFLE criteria, post-liver transplantation. Am J Transplant. 2007;7(1):168-76.

28. Chen J, Singhapricha T, Hu KQ, Hong JC, Steadman RH, Busuttil RW, et al. Post liver transplant acute renal injury and failure by the RIFLE criteria in patients with normal pretransplant serum creatinine concentrations: a matched study. Transplantation. 2011;91(3):348-53.

29. Davis CL, Feng S, Sung R, Wong F, Goodrich NP, Melton LB, et al. Simultaneous Liver-Kidney Transplantation: Evaluation to Decision Making. Am J Transplant. 2007;7(7):1702-9.

30. Fong TL, Khemichian S, Shah T, Hutchinson IV, Cho YW. Combined liver- 
kidney transplantation is preferable to liver transplant alone for cirrhotic patients with renal failure. Transplantation. 2012;94(4):411-6.

31. Fagundes C, Barreto R, Guevara M, Garcia E, Solü E, Rodrvguez E, et al. A modified acute kidney injury classification for diagnosis and risk stratification of impairment of kidney function in cirrhosis. J Hepatol. 2013;59(3): 474-81.

32. Piano S, Rosi S, Maresio G, Fasolato S, Cavallin M, Romano A, et al. Evaluation of the Acute Kidney Injury Network criteria in hospitalized patients with cirrhosis and ascites. J Hepatol. 2013;59(3):482-9.

33. Wei $Y$, Zhang $L$, Lin $H$, Li J, Li B, Yan L, et al. Factors related to post liver transplantation acute renal failure. Transplant Proc. 2006;38(9):2982-4.

34. Dehghani SM, Derakhshan A, Taghavi SA, Gholami S, Jalaeian H, MalekHosseini SA. Prevalence and risk factors of renal dysfunction after liver transplant: a single -center experience. Exp Clin Transplant. 2008;6(1):25-9.

35. Fonseca-Neto OC, Miranda LE, Batista TP, Sabat BD, Melo PS, Amorim AG, et al. Postoperative kidney injury does not decrease survival after liver transplantation. Acta Cir Bras. 2012;27(11):802-8.

36. Inoue Y, Soyama A, Takatsuki M, Hidaka M, Muraoka I, Kanematsu T, et al. Acute kidney injury following living donor living donor living transplantation. Clin Transplant. 2012;26(5):E530-5.

37. Biggins SW, Kim WR, Terrault NA, Saab S, Balan V, Schiano T, et al. Evidence - based incorporation of serum sodium concentration into MELD. Gastroenterology. 2006;130(6):1652-60.

38. Karapanagiotou A, Kydona C, Dimitriadis C, Sgourou K, Giasnetsova T, Fouzas I, et al. Acute kidney injury after orthotopic liver transplantation. Transplant Proc. 2012;44(9):2727-9.

39. Cantarovich M, Tchervenkov J, Paraskevas S, Ghali P, Wong P, Deschknes $\mathrm{M}$, et al. Early changes in kidney function predict long term chronic kidney disease and mortality in patients after liver transplantation. Transplantation. 2011;92(12):1358-63.
40. Pawarode A, Fine DM, Thuluvath PJ. Independent risk factors and natural history of renal dysfunction in liver transplant recipients. Liver Transpl. 2003;9(7):741-7.

41. Li C, Wen TF, Yan LN, Li B, Yang JY, Xu MQ, et al. Risk factors for in-hospital mortality of patients with high model for end-stage liver disease scores following living donor liver transplantation. Ann Hepatol. 2012;11(4):471-7.

42. Kundakci A, Pirat A, Komurcu 0, Torgay A, Karakayali H, Arslan G, et al. Rifle criteria for acute kidney dysfunction following liver transplantation: incidence and risk factors. Transplant Proc. 2010;42(10):4171-4.

43. Biancofiore $\mathrm{G}$, Davis $\mathrm{CL}$. Renal dysfunction in the perioperative liver transplant period. Curr Opin Organ Transplant. 2008;13(3):291-7.

44. Douthitt L, Bezinover D, Uemura T, Kadry Z, Shah RA, Ghahramani N, et al. Perioperative use of continuous renal replacement therapy for orthotopic liver transplantation. Transplant Proc. 2012;44(5):1314-7.

45. Ojo AO, Held PJ, Port FK, Wolfe RA, Leichtman AB, Young EW, et al. Chronic renal failure after transplantation of a nonrenal organ. N Engl J Med. 2003;349(10):931-40.

46. Gonwa TA, Mai ML, Melton LB, Hays SR, Goldstein RM, Levy MF, et al. End-stage renal disease (ESRD) after orthotopic liver transplantation (OLTX) using calcineurin-based immunotherapy: risk of development and treatment. Transplantation. 2001;72(12):1934-9.

47. Paramesh AS, Roayaie S, Doan Y, Schwartz ME, Emre S, Fishbein T, et al. Post-liver transplant acute renal failure: factors predicting development of end-stage renal disease. Clin Transplant. 2004;18(1):94-9.

48. Leithead JA, Ferguson JW, Hayes PC. Modifiable patient factors are associated with late decline in renal function following liver transplantation. Clin Transplant. 2012;26(3):E316-23.

49. Sharma P, Welch K, Eikstadt R, Marrero JA, Fontana RJ, Lok AS. outcomes after liver transplantation in the model for end-stage liver disease era. Liver Transpl. 2009;15(9):1142-8. 